\title{
AIR TRAFFIC CONTROL RESPONSE TO DELAYS - A SYSTEM STUDY OF NEWARK INTERNATIONAL AIRPORT
}

\author{
Antony D. Evans, John-Paul Clarke, MIT International Center for Air Transportation, \\ Cambridge, $M A$
}

\begin{abstract}
Airport delays are a significant problem in the United States air transportation system. Between 1999 and 2000 the number of flights delayed increased by 20 percent despite only a $0.4 \%$ increase in total operations. Newark International Airport (EWR), one of New York City's primary airports, is one of the airports in the United States most impacted by delays. Newark had the highest percentage of operations delayed in 1999, and was second only to LaGuardia Airport in 2000. Nearly $85 \%$ of delays at Newark are caused by adverse weather impacting an airport that may be characterized as having limited capacity and a very full schedule. Although Newark is heavily impacted by weather, delays have not increased significantly since 1998. This indicates that the airlines, air traffic control (ATC), and the Port Authority of New York and New Jersey have successfully adapted.
\end{abstract}

On June 29, 2000, a research team from MIT visited Newark airport to assess the effectiveness of any adaptations made, and to collect data on airline and ATC departure operations, and of the national and local weather affecting the airport. Airline and ATC personnel were also interviewed. Results of this study indicate that airspace capacity limitations downstream of the airport are a primary flow constraint at the airport, and that these constraints are the source of most surface delays. A number of tactical ATC responses to delays were examined, including the application of restrictions, re-routing with the help of the National Playbook, and the use of decision-aiding tools such as the Dynamic Spacing Program (DSP) and the Integrated Terminal Weather System (ITWS). Improved interfacility communications and further utilization of runway 11-29 were identified as other tactical responses to delays, whilst the formation of the Air Traffic Control System Command Center and the New York Airspace redesign were identified as the key strategic ATC responses to delays. Particularly the New York airspace redesign has great potential to reduce delays at the airport.

Because delays at Newark are caused by downstream flow constraints, the responses at the airport can be applied to other airports as delays from downstream constraints increase. Such an increase in delays system wide from downstream constraints is inevitable as the system becomes more congested.

\section{Problem Definition}

\section{Introduction}

The demand for air travel continues to increase at between 3 and 5\% each year, but system capacity has become difficult to increase accordingly. Consequently airport delays have progressively become a very significant problem in the U.S. air transportation system, increasing by between $20 \%$ and $25 \%$ per year [1][2][3].

One of the most delayed airports in the United States is Newark International Airport (airport code EWR). Newark is one of the three primary airports in the New York Metropolitan area, the others being John F Kennedy International Airport (JFK) and LaGuardia Airport (LGA). In 1999 Newark had the highest percentage of delayed operations of all airports in the United States, at $7.9 \%$, and the highest average Air Traffic Control (ATC) departure delay of any airport in the United States, at 19.5 minutes [4]. However, comparing the delay history at Newark to that of the entire system, in Figure 1, it is clear that since 1997 delays have increased at a slower rate at Newark than system wide. From 1999 to 2000 , delays increased by only $1.6 \%$, compared to the $20 \%$ increase system wide. It thus appears that the Federal Aviation Administration (FAA), the airlines and the Port Authority of New York and New Jersey (PANYNJ) 
have been able to adapt their operations to reduce delays. This study thus examines the operations at Newark, and responses to delays, to determine the responses that were most effective in reducing delays.

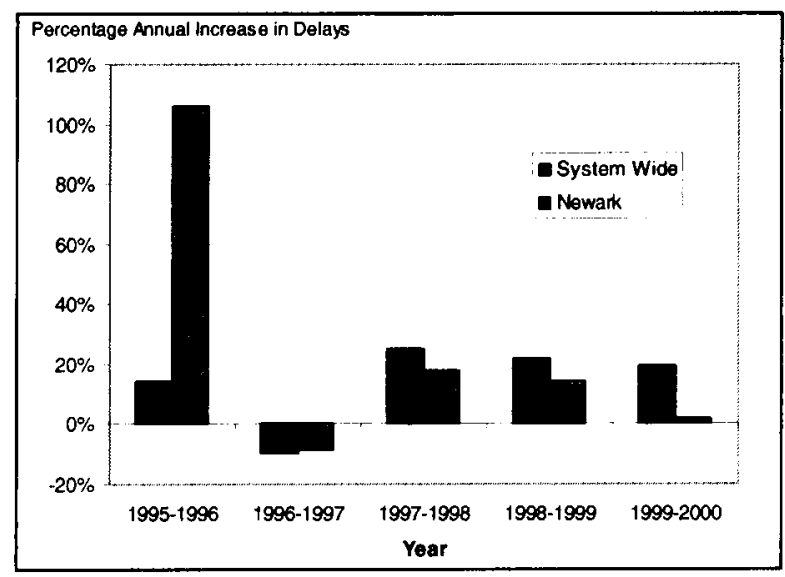

Figure 1. Number of operations delayed at Newark airport, and system wide [2].

\section{Cause of Delays}

According to the FAA [4][5], 68.7\% of ATC delays in the National Airspace System (NAS) were caused by weather, both in 1999 and 2000. At Newark $84 \%$ of arrival delays were identified to be related in some way to weather, in 1999, according to a study by Allan, Gaddy and Evans, at Lincoln Laboratories [6]. Comparing the delay history at Newark to annual precipitation [7] there is a clear correspondence between the high delays in 1996, which breaks away from the trend of the rest of the data, and particularly high precipitation that year, further suggesting that weather has a particularly significant impact on the airport.

Weather delays are caused by airport sensitivity to adverse weather, the frequency of adverse weather at the airport, the schedule operated by airlines relative to the capacity of the airport, and airspace congestion in the terminal area. The decrease in airport capacity induced by adverse weather is only slightly higher at Newark than the average of the 31 busiest airports in the United States [8]. The source of this sensitivity is related primarily to runway limitations, and to limitations in gate space. The frequency of adverse weather at Newark is also higher than the average for the 31 busiest airports in the US, but not to a significant degree. However, combining these two factors, Newark is the 5th most weather-impacted airport of the 31 busiest airports in the US. The impact of weather, however, affects delays according to the schedule operated at the airport. In 2000 Newark was scheduled beyond IFR (Instrument Flight Rules) capacity, and in some cases beyond VFR (Visual Flight Rules) capacity. Because of the flat un-banked schedule operated at the airport there are also few recovery periods, and consequently delays propagate throughout the day. Airspace congestion further increases delays.

Because of the close proximity of Newark to three other significant airports, operations and delays at each airport impact the others. There are also constraints on the airspace that can be used by each airport, limiting the ATC response capabilities.

\section{Newark ATC and Airline Operation}

Newark airport operates within the New York TRACON (Terminal Radar Approach CONtrol) and New York ARTCC (Air Route Traffic Control Center). A simplified map of the New York airspace is shown in Figure 2. The map shows the primary departure fixes used at Newark. These are:

- GAYEL and COATE are generally used for northwest bound traffic.

- ELIOT, PARKE, LANNA and BIGGY are generally used for traffic to the west, the southwest, and the south.

- WHITE is generally used for traffic to the South, to Florida, and to Central and South America.

- GREKI and MERIT are generally used for traffic to the north, and to Europe.

The traffic flow through the fixes is regulated through the application of restrictions, which may include Mile in Trail (MIT) restrictions, approval requests (APREQs), fix closures and ground delay programs (GDPs). If a specific route has severe restrictions or is closed, aircraft are re-routed. However, dynamic re-routing is difficult because of the extensive inter-facility communication and cooperation required. Consequently the National Playbook, a set of preplanned reroutes for specific fix and jet-route closures, has been developed. While useful in many scenarios, the playbook has limitations, the foremost being that the plays in the 
playbook are often not enough to solve the problems alone.

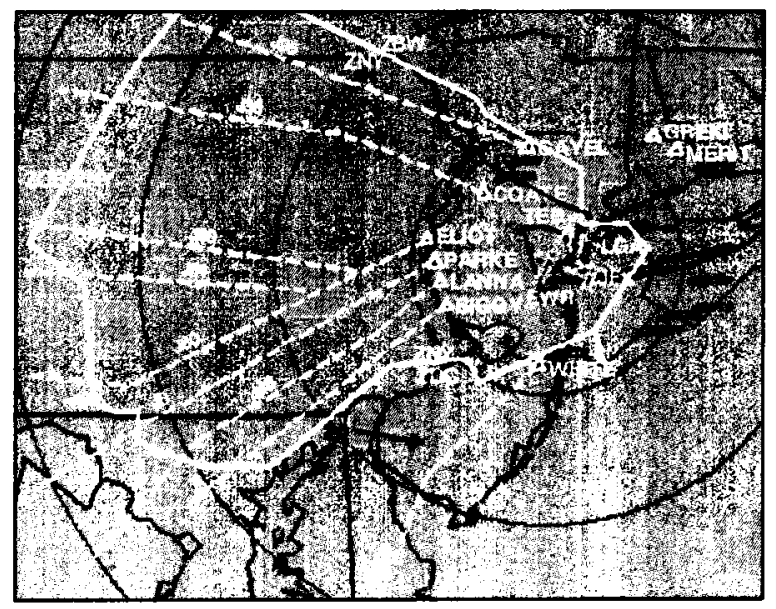

\section{Figure 2. Primary departure fixes for Newark International Airport.}

Newark airport has three terminals, Terminal A, B and C. Terminal A is used for operations for most domestic airlines, except Continental, which uses Terminal C. Terminal B is used for international arrivals. Continental operates a hub at the airport, and including Continental Express, operates approximately $55 \%$ of operations at Newark, making it the dominant airline. Continental operates a ramp tower at the airport, and during adverse weather is given control of an extended ramp area according to a letter of agreement with the FAA. This enables Continental to perform presequencing of its aircraft before they are transitioned to FAA control.

\section{System Dynamics in Adverse Weather - Site Visit, June 29, 2000}

In order to identify the causes of delays at Newark, the weather, air traffic control, and airline performance was studied in detail during a period when operations at Newark were severely restricted, i.e. June 29,2000 . This was a day severely impacted by summer thunderstorms, and just before the "Fourth of July" weekend, when demand for air travel was high. The summer of 2000 has also become known as the "worst summer ever", being the worst period of airport delays in history. Data was collected and operations observed at the New York TRACON, the Newark ATCT (Air
Traffic Control Tower), and the Continental Newark ramp tower.

\section{Weather and Restrictions}

On June 29, 2000, Newark was impacted by two fronts. The first extended from Maine to Mississippi, and moved east, impacting west and south departures throughout the day. The second, initially over Lake Eerie, also moved east, impacting primarily northeast and west departures through the afternoon and evening. After the application of historically validated restrictions (HVRs) in the morning, some restrictions were lifted, until the afternoon when heavy restrictions and eventually a number of fix closures were implemented. By 16:00 EDT all west and south fixes, and one of the two north departure fixes, were closed. No re-routes were implemented until after 18:00 EDT. Except for a few exceptions the restrictions correlated closely to the local weather. A simplified Gantt chart of the restrictions is presented in Figure 3.

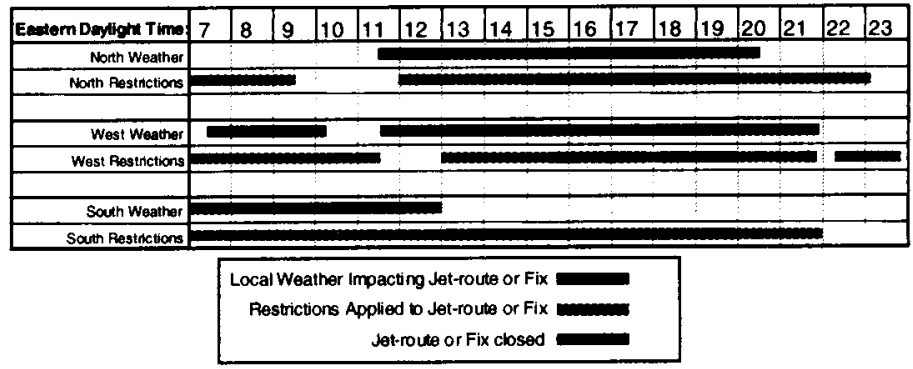

Figure 3. Simplified EWR departure restrictions and local weather - June 29, 2000.

\section{Impact of Restrictions}

The impact of the restrictions on the departure rate was examined by comparing the departure schedules as filed by the airlines, the modifications made by ATC, and the actual departure rate. Data indicated that a number of flights were rescheduled by ATC from the period when all the primary west and south fixes were closed, to later in the evening. The long-term shape of the actual departure rate coincides closely with the ATC modified rate, although short-term differences are significant.

The impact on delays can be determined by examining a running plot of the total departure delay for all aircraft waiting to depart from Newark with the restrictions applied. The total departure delay running through the day, calculated by 
summing the difference between actual wheels off time and scheduled wheels off time for every aircraft waiting to depart the airport, corresponds closely to the restrictions applied, as seen in Figure 4. It is precisely when the fix closures are applied that the total delay climbs most steeply, and only when the fixes are reopened that that total delay begin to decrease again. Even when the west fixes are closed briefly later in the evening, the total delay shows a second peak, before again decreasing as the fixes are reopened.

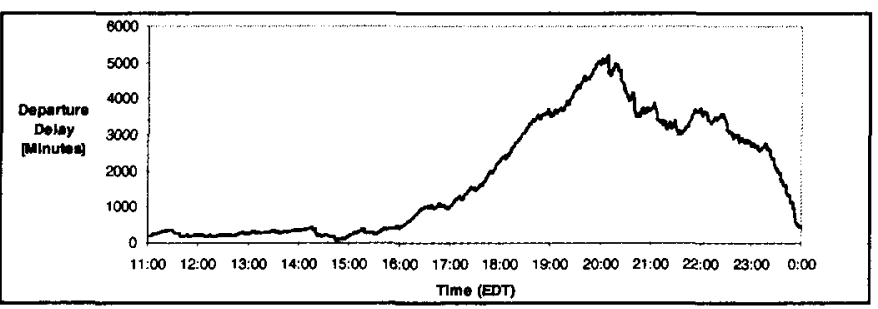

Figure 4. Running plot of total departure delay of aircraft waiting to depart from EWR.

\section{Key Problem Definition}

The key conclusion drawn from the site visit on June 29,2000 is that downstream airspace capacity limitations were a primary flow constraint and the primary cause of surface delays. Weather was clearly the primary cause of the restrictions, seen by the correspondence between the local weather on the respective fixes and the restrictions applied to those fixes. The propagation of these external constraints to the airport surface was seen in how the decreases in departure rate appeared to correlate closely to those periods when restrictions were most severe. Departure delays also clearly correlated very closely with the periods of severe restriction.

\section{Air Traffic Control Responses to Delays}

Pressure from both the public and from congress has forced the FAA to respond to the severe delays in the NAS. FAA Administrator Jane Garvey has spoken about ATC delays and capacity before congress a number of times, including a statement specifically dedicated to air traffic congestion in the New York Metroplex on July 16, 2001 when testifying before the Committee on
Transportation and Infrastructure, Subcommittee on Aviation [9]. Correspondingly, ATC has responded to the delays at Newark in a number of ways. These are discussed in detail below.

\section{Tactical ATC Responses to Delays}

Tactical responses by ATC include:

- The application of restrictions to fixes or jetroutes.

- Re-routing of aircraft, and the utilization of the National Playbook for formulation of reroutes.

- Utilization of decision aiding software such as the Departure Spacing Program (DSP) and the Integrated Terminal Weather System (ITWS), for improved ATC decisionmaking.

Furthermore, the following responses have been questioned as to their potential to reduce delays:

- Inter-facility communication.

- The utilization of runway $11 / 29$.

These are presented in the sections below.

\section{Fix Restrictions}

The application of restrictions to fixes and jetroutes is the primary ATC response to adverse weather. Limiting the number of aircraft using a specific fix or jet-route when that fix or jet-route is impacted by weather is essential to ensuring the safety of the NAS. These restrictions result in delays at airports as demand for capacity exceeds supply. Detailed observations were consequently made of the restrictions applied to the primary departure fixes for Newark airport, on June 29, 2000

Figure 5 shows a Gantt chart of the restrictions on the departure fixes, and a local Doppler radar map at 11:00 EDT. The Doppler radar map shows the weather moving east, off the coast. At this time it was no longer having a direct impact on the southern west fixes, but continued to impact WHITE in the south. WHITE was correspondingly restricted to $20 \mathrm{MIT}$. The HVRs were complete, leaving the north and northern west fixes unrestricted. However a 20 MIT restriction had been applied to PARKE and a 40 MIT restriction applied to BIGGY. According to the Gantt chart 
this fix was also closed briefly, at 9:20am. However, it is clear that BIGGY was not impacted by local weather, so these restrictions must have been the result of capacity constraints further away from the airport. Figure 6 thus shows the national weather over the destination cities with preferred routings from Newark through BIGGY. These cities were clearly severely impacted by the front extending from off the coast of New England down to the Gulf of Mexico. It is thus downstream weather that is the cause of the restrictions, and not local weather. This was also the case for PARKE and LANNA, although LANNA remained unrestricted because the level of traffic through this fix was light.

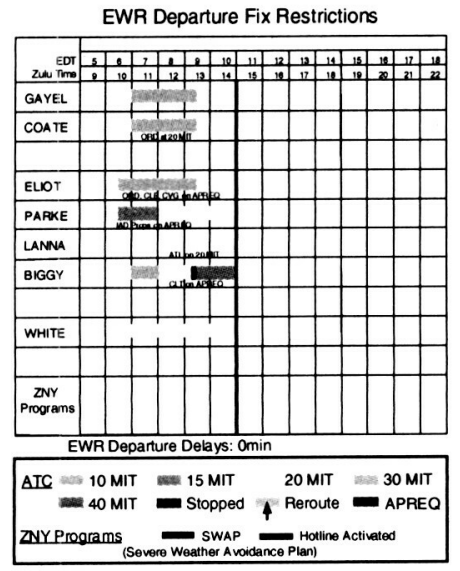

North-east fixes unrestricted throughout day

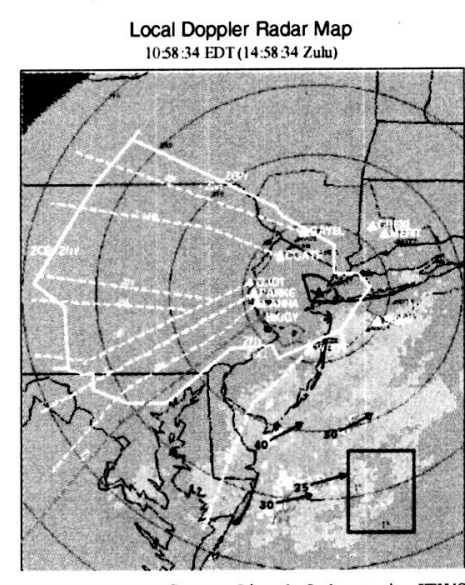

Source: Lincoln Laboratories ITWS
Figure 5. Restrictions and local Doppler radar map - 11:00 EDT (15:00 Zulu).

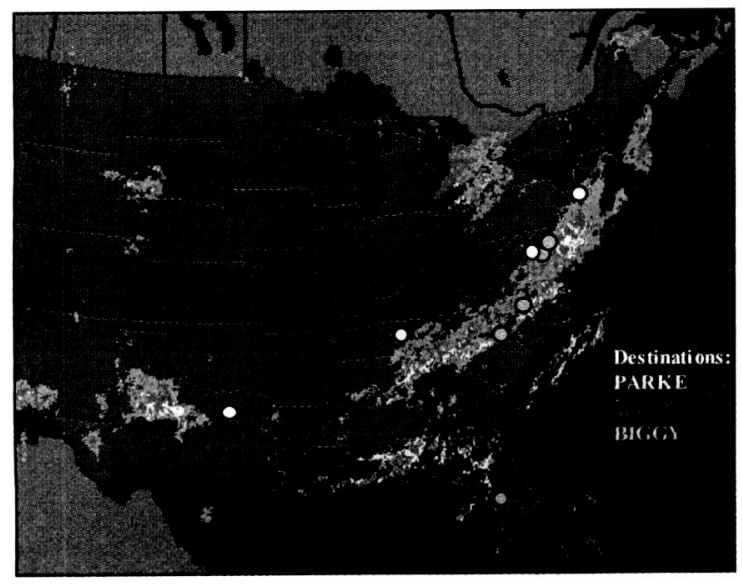

Figure 6. National Doppler radar map 10:30:00 EDT (14:30:00 Zulu).

Figure 7 shows the Gantt chart and local Doppler radar map at 13:00 EDT. At this time the weather to the south of the airport had continued to move off the coast, now no longer impacting WHITE locally. However, the front originally over Lake Eerie had started to impact the north and northern west fixes locally. The weather to the northwest of the airport, although somewhat sparse, was severe in places. Consequently GAYEL and COATE had been restricted to 10 MIT. ELIOT and PARKE, the two northern west fixes, were however unrestricted, despite local weather, and instead LANNA and BIGGY were restricted, to $40 \mathrm{MIT}$. WHITE was also closed at this time, despite no local weather. As can be seen in Figure 8 these restrictions were again caused by downstream weather severely impacting the majority of destination cities for flights from Newark with preferred routings through these fixes. ELIOT and PARKE, although impacted by local weather, were unrestricted because of light traffic (at 13:00 ELIOT was 5 aircraft per hour, and PARKE, 0 aircraft per hour). This suggests that it is not only the weather that affects restrictions, but also the amount of traffic through the fixes. By 15:00 EDT the flow rate on ELIOT had increased to 25 aircraft per hour, whilst PARKE remained low at 2 aircraft per hour. Correspondingly ELIOT was restricted to 20 MIT, whilst PARKE remained unrestricted.
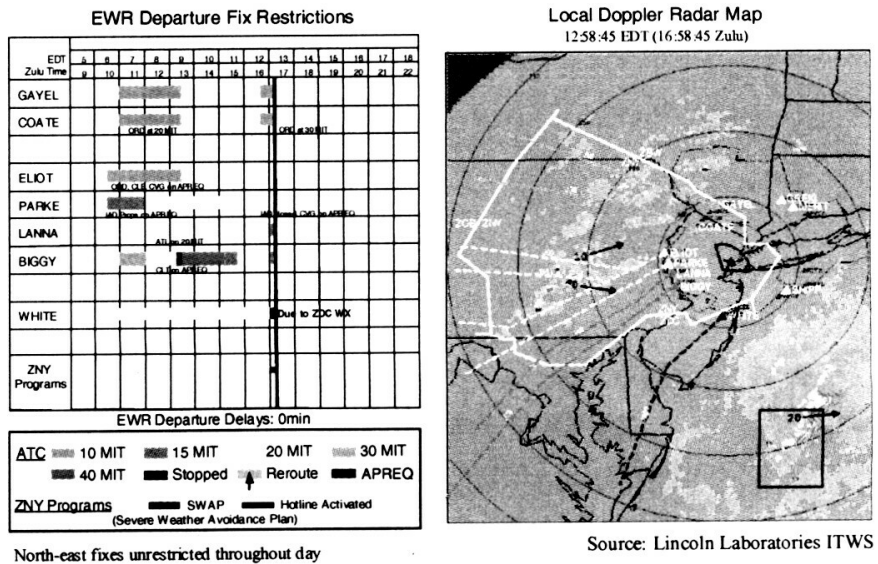
Figure 7. Restrictions and local Doppler radar map - 13:00 EDT (17:00 Zulu).




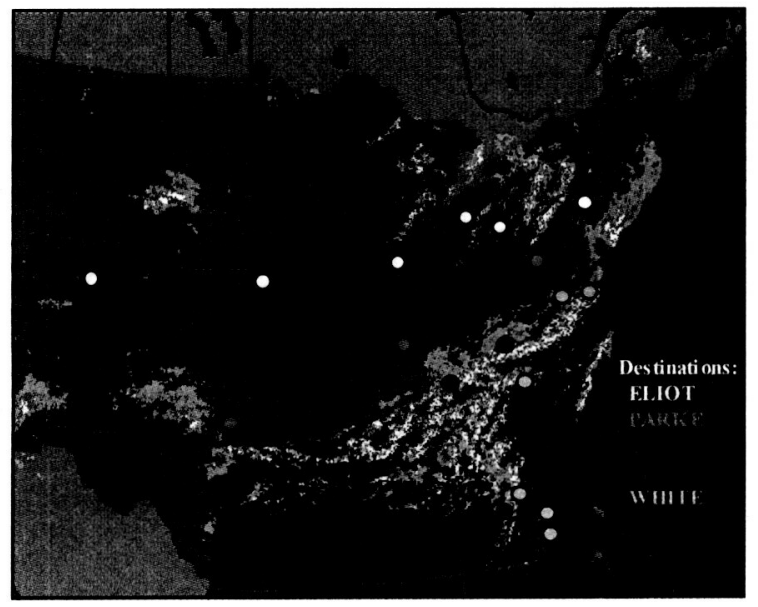

Figure 8. National Doppler radar map 12:30:00 EDT (16:30:00 Zulu).

The severe weather avoidance plan, and FAA delay program which blocks off large chunks of airspace in regions where thunderstorms are reported, also went active at 13:00 EDT. This was because of the severe restrictions to the west, and the closure of WHITE, the primary southbound fix. At 15:00 EDT the hotline, a direct and continuous telephone communication between all the facilities in the area, was activated.

It is clear from the above discussion that it is not simply local weather that affects restrictions, but rather a coupling of local weather, downstream weather, and traffic demand. Each of these factors should thus be addressed in the development of tools designed to aid decision making in the implementation of restrictions.

\section{Re-routes}

Re-routing aircraft from their original flight plan onto a new less restricted route is a preferred method for dealing with severe fix or jet-route restrictions. The reason for this is that re-routes around sections of the flight path that are severely restricted can reduce delays on routes that would otherwise be severely delayed. Figure 9 shows an example of two routes, with two components each a fix or jet-route local to the origin airport, and a downstream fix or jet-route. If the two routes were separate a local or downstream constraint would stop the flow on that route. However, if re-routes between routes were allowed, shown by the dashed lines, the local weather on one route would not impact the flow to the destinations on that route, as aircraft could be re-routed onto the other route locally, and returned to their original route after the local constraint. Similarly if one route had local constraints and the other had downstream constraints, flow on the route with downstream constraints could be lightly restricted, and traffic from the route with local constraints re-routed onto it, before being re-routed back, after the local constraints. If correctly planned, this could leave the level of traffic on the fix with downstream constraints low enough to meet the restrictions required downstream.

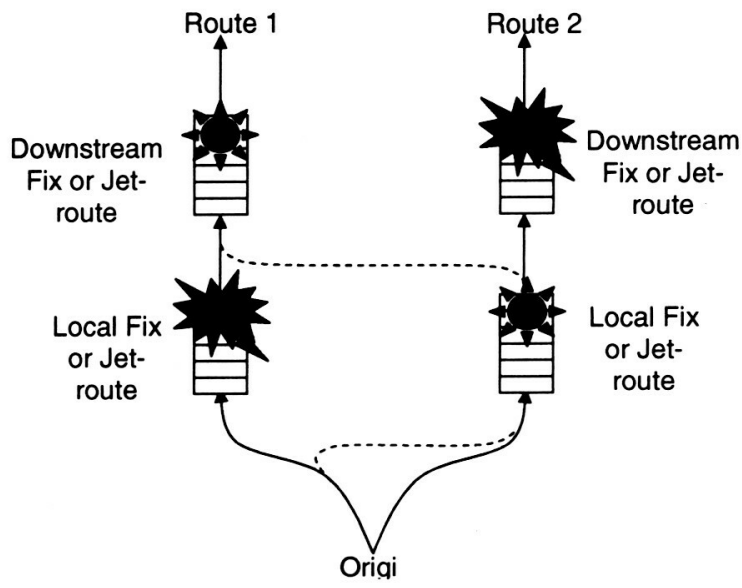

Figure 9. Advantages of re-routing.

Despite its benefits, re-routing is, however, difficult to implement, as all facilities affected need to agree on a re-route, which is coordinated through the ATCSCC. This may often involve a number of facilities with conflicting interests. Because of these difficulties the National Playbook was developed, which provides suggestions for re-routes. On November 15, 16 and 17, 2000, the Newark ATCT, Port Authority of New York and New Jersey, New York TRACON, and New York ARTCC, were visited and controllers interviewed. According to these interviews the National Playbook is well respected and the re-routes implemented are generally taken directly from the Playbook. During the June 29, 2000 site visit to Newark Airport, however, controllers did not use the Playbook extensively. This was because plays did not exist for the weather scenarios that impacted the airport. The Playbook can only be used for the specific weather scenarios in the book. A detailed examination of those re-routes implemented, however, follows. 
Figure 7, which shows the restrictions and local Doppler radar map for 13:00 EDT, clearly shows a gap between the two fronts, through which WHITE and J209 pass. This gap grows as the day progresses. It appears initially that this gap could allow traffic to fly west by departing through WHITE and flying west around the south of the front coming through from the north west.

However, this would require that the aircraft change their flight plans from flying from New York Center to Cleveland Center, to flying from $\mathrm{New}$ York Center to Washington Center, and then to Cleveland Center from the south. Because this reroute crosses center boundaries it would have required extensive coordination between the three Centers, through the System Command Center (ATCSCC). New York arrivals from the south also pass through this corridor, and Washington arrivals and departures use the airspace just south of the front from the northwest. The flights would be interacting with traffic to and from Washington Dulles (IAD), Washington National (DCA), Baltimore (BWI) and Philadelphia (PHL). With improved inter-facility coordination however, this gap in the weather may have been able to be utilized, allowing much traffic out to the west.

Figure 10 shows the Gantt chart and local Doppler radar map at 16:15 EDT. The weather from the northwest continued to move towards New York City, and can be seen to impact the north and west departure fixes. Because of the local weather COATE and all the west fixes were closed, which are the departure fixes with the highest traffic. WHITE remained closed because of downstream weather, although some re-routes were allowed though the gap between the two fronts to Norfolk (ORF) and Charlotte (CLT). The traffic to these destinations was however light in comparison to that scheduled through the west fixes, and the original flights plans also took the flights through the same ARTCCs.
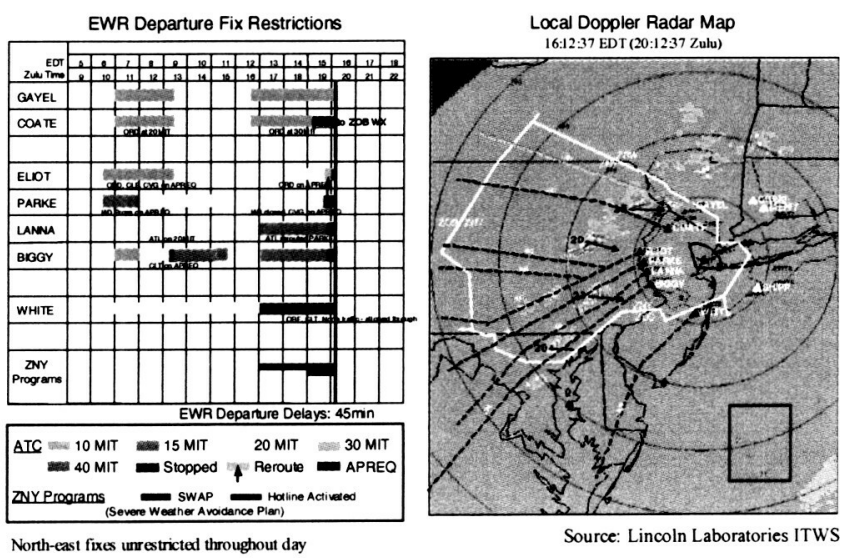

\section{Figure 10. Restrictions and local Doppler radar map - 16:15 EDT (21:15 Zulu).}

One of the plays in the National Playbook, called NO-WESTGATES/RBV_1 is designed for use when all west departure fixes are closed. This play however re-routes aircraft through COATE and WHITE, both of which were closed on June 29 when the west fixes were closed. This re-route was thus not available. The only open fixes were those to the northeast. There is a play in the National Playbook called TOP-THE-WX_1, which is a special request routing for "topping the weather", where if all the west fixes are closed west departures fly through MERIT, to the northeast, in order to cut back to the north of the weather. However, when the west fixes were closed on June 29, there was heavy traffic flying to Europe so these fixes were also not available.

Figure 11 shows the Gantt chart and local Doppler radar map at 19:00 EDT. Although ELIOT and PARKE were closed by 7 pm, BIGGY was reopened, and all westbound traffic was re-routed onto that fix. This re-route is not however specified in the National Playbook. No play is described for the closure of three of the four west fixes, although some plays for other closures do re-route traffic onto BIGGY, such as the play for the closure of jetroute J6 (NO-J6_3). The re-route of traffic onto BIGGY is not likely to have required difficult coordination because the traffic continued to be westbound. 


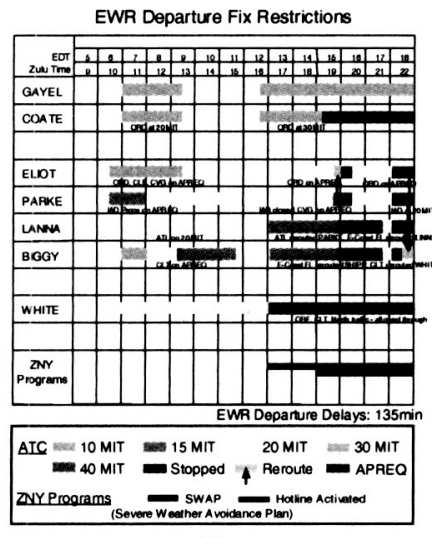

Norh-east fixes unrestricted throughout day

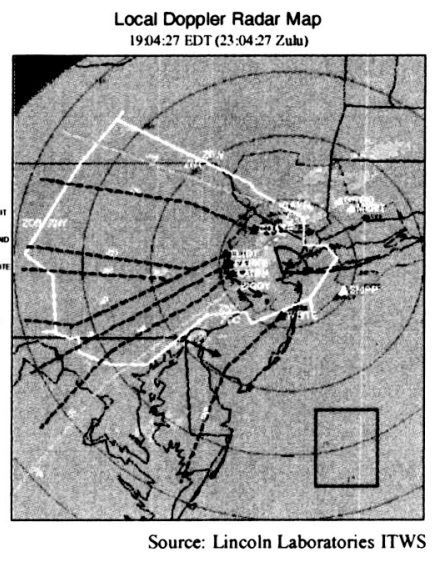

Figure 11. Restrictions and local Doppler radar
map - 19:00 EDT (23:00 Zulu).

Because the National Playbook can only be utilized for weather situations for which plays are developed, it can only be utilized for a severe weather situation if a play is developed for that situation. It is thus essential that plays continue to be developed and the Playbook updated. However, even the Playbook re-routes can be rendered unusable by constraints on the destination fixes.

It is not clear to what degree inter-facility coordination would have had to be improved to have allowed the re-route through the gap between the fronts, from $3 \mathrm{pm}$ to $5 \mathrm{pm}$ on June 29 , to be applied. It does appear however that re-route opportunities would be greatly improved by more efficient inter-facility coordination.

\section{Decision-Aiding Tools}

A number of decision aiding tools have been developed to improve communication and information flow in ATC. These include the Enhanced Traffic Management System (ETMS), General Information (GI) Message System and Flight Data Information Operation (FDIO), Information Display System-4 (IDS-4), the System Command Center Operations Information System (OIS) Website, Doppler weather radar displays, Departure Spacing Program (DSP), and Integrated Terminal Weather System (ITWS). DSP and ITWS particularly are two recently introduced decisionaiding tools designed specifically as delay problems within the NAS have become a primary focus of the FAA.

DSP is a tool that uses dynamic air traffic information from specially adapted airports to schedule flights though common departure fixes. This tool provides controllers and Traffic Management Coordinators (TMCs) with the ability to space departing aircraft. However the tool also improves efficiency by reducing voice coordination between the ATCT, the TRACON and ARTCCs, and providing a dynamic flight plan, ATC information, and reports. DSP also provides departure controllers and TMCs with the aircraft ground lineup status for aircraft departing from each airport runway in the system [10]. In April, 2000 DSP was installed at Newark, LaGuardia, JFK, and Philadelphia ATCTs; New York and Philadelphia TRACONs; and New York ARTCC.

According to interviews carried out on November 17, 2000, DSP is a great benefit to the New York Departure Pit Complex (NYDP) at the New York ARTCC, which issues departure clearances to each departing aircraft. This is because DSP is able to check flight plans automatically according to preferential departure routings, and thus enables NYDP controllers to issue clearances electronically, doing away with flight strips in the NYDP. The tool was also described as useful for ensuring the efficient utilization of open fixes and for coordination of aircraft departure times for better system efficiency. However, it does not provide any assistance in optimizing routes or assignment of re-routes. In contrast to its use at the ARTCC, according to interviews on November 16, 2000 DSP is not used extensively at the New York TRACON. The tool was described as powerful but requiring more airports to be truly useful to the TRACON.

ITWS is a system that is designed to provide safety and planning tools to all terminal aviation system users, by providing improved weather information. The system was developed initially by MITs Lincoln Laboratories, and further by Raytheon and TRW. It is designed to characterize current terminal weather situations and forecast 30 minutes into the future, presenting the data on a Doppler radar map. ITWS includes wind shear and microburst predictions, storm cell and lightning information, terminal area winds aloft, runway winds, and short-term ceiling and visibility predictions. The ITWS demonstration system was introduced in New York in the fall of 1998, and its capability extended to include 30 minute . 
predictions of convective storms in the summer of 1999. The system is currently operational at Newark, Teterboro, LaGuardia and JFK ATCTs; the New York TRACON; New York, Boston and Washington ARTCCs; and the ARTCSCC in Herndon, VA. American, Continental, Delta, Federal Express, Northwest, Southwest, United, UPS and US Airways also either have access to the situation display or Internet access to ITWS.

According to interviews on the June 29, 2000 site visit, a visit to the Newark ATCT, New York TRACON and New York ARTCC on November 15-17, 2000, and a visit to Continental at Newark June 14 and 15, 2001, ITWS has been well received and is used routinely. However, as ITWS only characterizes the terminal area, controllers expressed a desire to also see ITWS applied further afield than the Terminal Area. National weather maps from the Internet are thus generally used in conjunction with ITWS. Despite this, according to a study by Lincoln Laboratories [6] ITWS provides an annual delay reduction of over 49,000 hours, which has a monetary value of over $\$ 150,000,000$ per year. The study also shows that delays could be further reduced if ITWS were extended to provide prediction of thunderstorm decay, and the onset and ending of capacity limiting events such as low ceiling or high surface winds.

Both DSP and ITWS appear to have been successful in improving decision aiding within ATC operations. Both can however be further developed, including the inclusion of more airports in the DSP system, and the extension of ITWS to include weather further afield. It is also recommended that the integration of both tools with other decision aiding tools be considered, so as to maximize their effectiveness and benefit to the system.

\section{Communication}

Another way in which delays can be reduced is by increasing the efficiency of strategic communication and coordination within the air traffic control system. Strategic communication and coordination has been recognized as a critical area in which system efficiency can be improved, leading to the development of the Collaborative Decision Making (CDM) initiative, developed to improve communication between ATC facilities and the airlines. The initial prototype operation was implemented in January 1998, at Newark and San
Francisco, and it was expended to all airports in September 1998. This initiative has lead to traffic management tools that aim to increase information sharing between parties whilst reducing the requirements for coordination. The traffic management tools developed through this initiate have been effective at improving communication between ATC and the airlines, but according to Davison and Hansman [11] the effectiveness of the CDM initiatives can be further enhanced by their application to the ATC system internally, particularly to inter-facility communications. Davison and Hansman identify a number of emergent themes, including an ambiguous organizational structure, information flow issues, awkward and unorganized communications and coordination, and organizational cultural issues. A number of recommendations are made including further centralization of authority to the ATCSCC; proceduralization of the communication of new or revised restrictions; proceduralization of commonly used re-routes; and restructuring teleconferences and hotlines.

\section{Utilization of Runway 11-29}

Runway 11-29 is the third runway at Newark airport, after the parallel runways. This runway has limited utilization and more use would definitely add capacity. However there are significant limitations to its use. Firstly, there are complications resulting from operations on the runway interacting with arrivals and departures to and from the other airports in the area, particularly LaGuardia and Teterboro airports. Secondly, there are also limitations on the types of aircraft able to depart on the runway, because of its length. The runway is only $6,800 \mathrm{ft}$ long. Assuming sea level performance, standard conditions, maximum take off weight, and a dry runway surface, the only aircraft operated by Continental able to depart from the runway are the Boeing 737-700, the Embraer RJ135, the Embraer EMB-120 and the Aerospatiale ATR 42-320. This means that the majority of aircraft operated at the airport cannot use the runway, and must instead operate from the parallel runways. Continental airlines are also converting from using turboprop aircraft such as the ATR 42320 , to using regional jets, such as the ERJ135 and ERJ145 (which cannot depart from runway 11-29). The result is further reduced utilization of runway 
11-29, and increased use of the already congested parallel runways.

Operations are also limited by interactions with the two parallel runways at Newark, introduced with the extension of the parallel runways to cross runway 11-29. Simultaneous operations of runway 11-29 and runway $22 \mathrm{R}$ have subsequently been restricted through a number of procedures [12]. Arrivals on the runway are also affected by the requirement to use LAHSO (Land and Hold Operations) in order to hold short of runway $4 \mathrm{~L}-22 \mathrm{R}$. At the time of the runway extension pilot unions contended that the FAA had not done enough to ensure that LAHSO was safe and had recommended that their members refuse to use the procedure. Consequently LAHSO had received bad press and added to the reduced utilization of the runway 11-29.

It is also recommended that steps be taken to improve coordination with Teterboro and LaGuardia, so as to allow increased utilization of the runway. Particularly also, the New York airspace redesign should take this factor into account.

\section{Strategic ATC Responses to Delays}

Strategic responses by ATC include the development of the Air Traffic Control System Command Center (ATCSCC) in Herndon, VA, and the redesign of the New York airspace.

\section{ATCSCC}

The role of the Air Traffic Control System Command Center (ATCSCC) is to manage the flow of approximately 50,000 aircraft operations per day within the continental United States. The facility strives to balance air traffic demand with system capacity and safety, and has been operational since 1994. The formation of the ATCSCC, and the CDM initiative, which began in 1998, lead to a change in the organizational structure of the ATC system. The primary change was from a decentralized structure to a more centralized structure, with authority centralized to the ATCSCC. As identified by Davison and Hansman [11], the ATC system has aspects of a centralized hierarchical structure at the national level, in that the ATCSCC's responsibility is to maintain efficiency throughout the other ATC facilities. However, each ATC facility ultimately still functions autonomously, without being under the authority of the ATCSCC, revealing a more decentralized structure at the local level. This creates ambiguity in the organizational structure, which affects coordination at the local level. [11]. As identified by Davison and Hansman [11], further centralization of authority to the ATCSCC would reduce the ambiguity of the organizational structure. However it would also relinquish flexibility at the local level.

\section{New York Airspace Redesign}

The New York airspace redesign is part of the FAA's National Airspace System Operational Evolution Plan, which intends to identify solutions to increase terminal throughput; to reduce en-route congestion by increasing flexibility; to keep terminal throughput closer to visual levels in all weather conditions; and to increase flexibility to cope with en route severe weather [13]. The objective to increase terminal throughput includes redesigns of a number of terminal areas in the United States, including that of New York and Philadelphia.

The New York airspace redesign is still in its development stages. However according to Chairman of the House Subcommittee on Aviation Rep. John Mica, speaking after a congressional hearing looking at ways to alleviate congestion at New York City airports on July 16, 2001, the FAA's airspace redesign program is a top priority to cut down on delays, particularly at LaGuardia. According to FAA Administrator Jane Garvey, who spoke at the same hearing, it will not however be completed until late 2005 or early 2006. [14]

The purpose of the New York airspace redesign is to identify ways to increase the efficiency of air traffic flows into and out of the metropolitan area, including Philadelphia, whilst still maintaining or improving the level of safety and air traffic services that are currently in place. This is necessary to respond to the increased demand for air travel, which requires increased system reliability, and thus a reduction in delays. Some of the direct results of the redesign are reduced delays at major airports, reduced pilot and controller workload, enhanced safety, and reduced adverse environmental impacts such as noise and air emissions. [15] 
The redesign is to incorporate a number of strategies developed to reduce congestion and environmental effects. These include increasing the altitude of arrivals, keeping them higher for longer, and faster climb to altitude for departures. Flights are also to be dispersed or concentrated over highways, industrial areas, and other less noise sensitive areas, in order to reduce the noise influences on the community. Advanced navigation tools are also to be implemented to reduce conversations between the pilot and controller.

Four alternative concepts that utilize these strategies have been proposed for the redesign, as follows:

1. Modify the current system, without redesigning it from the ground up. This would incorporate the above strategies but little more.

2. White paper approach - complete redesign, keeping only the runways. The new structure would be similar to the four corner concepts at Chicago O'Hare (ORD), Atlanta (ATL), Denver (DEN), and Dallas/Fort Worth (DFW). The New York and Philadelphia airports would all be treated as a single airport until defined points within the airspace at which point the aircraft would be separated to their respective airports. This would mean that if one arrival route was busy aircraft could be offloaded onto other arrival routes, regardless of their destination airport.

3. A hybrid between the white paper approach and the current system.

4. All departure operations out over the ocean. This alternative, although relatively simple in design, is complicated politically. It is strongly supported by the communities of New Jersey, but not others.

The New York airspace redesign is likely to be the most significant change to the air traffic control system structure, and is also thought to be the most likely response to achieve significant reductions in delays. This is however very dependent on the solution chosen, and the ability of the redesign process to avoid bureaucratic inertia, such as would occur by attempting to completely satisfy all of the stakeholders, many of whom have contradicting interests.

\section{Other Strategic Solutions}

Newark is constrained by the limited number of runways it operates. The addition of a new runway, however, is not a feasible solution at this time. Any new runway would need to be built alongside the parallel runways, but sufficiently far from them as to allow for simultaneous operations. This would however require the new runway to be built where Interstate I-95 is currently located, and it is not considered feasible to move this interstate because of the presence of the Newark harbor to its east. Newark is thus not likely to receive a new runway in the foreseeable future.

Demand management has also been proposed as a solution to reduce congestion at the airport. Currently Newark operates slot control at Terminal B only. According to interviews with Susan Baer, General Manager at Newark International and Teterboro Airports for the Port Authority of New York and New Jersey, on November 15, 2000, further slot control is being considered, as is peak hour pricing.

\section{Conclusions and Policy Implications}

In 2000 Newark airport had the highest ATC delays in the country, and was second only to LaGuardia in percentage of operations delayed. The cause of delays at Newark was primarily weather, with $84 \%$ of arrival delays related in some way to weather. The weather's impact on the airport is related to the sensitivity of the airport to adverse weather and the frequency of adverse weather. Newark then operates a very full, flat schedule, with few recovery periods. The airspace is also highly congested, Newark being one of four primary airports in the New York Metroplex. According to a site visit to the airport on June 29, 2000, the primary flow constraint, which leads to the high surface delays at the airport, is downstream airspace capacity limitations.

ATC Responses to the delays at Newark have been both tactical and strategic. Tactical responses include application of restrictions and reroutes, and the use of decisions aiding tools. Other suggested responses include improved inter-facility communication and increased utilization of runway 11-29. Strategic responses to delays in the system include the formation of the ATCSCC, and a redesign of the NAS. A number of conclusions 
related to these responses were identified, as described below.

Restrictions are implemented not only because of local weather, but are also affected by downstream weather and traffic levels through the departure fixes. It is recommended that ATC decision aiding tools be developed that account for all of these factors. Integration with current systems such as ITWS and DSP is also essential.

Dynamic re-routing is difficult because of the need for all the facilities to be in agreement for a reroute to be approved. With improved inter-facility communication re-routing could thus be utilized to a greater extent, and thus delays reduced. It is thus recommended that steps be taken particularly to improve inter-facility communication, which may include the further development of decision aiding and communication tools. The National Playbook, developed to suggest re-routes and improve their utilization, although useful, needs to be further developed to include more plays. These would address combinations of fix closures not addressed in the current edition of the playbook.

Two decision-aiding tools, DSP and ITWS, have recently been implemented at Newark and its associated ATC facilities. DSP is a great benefit to the NYDP at the New York ARTCC and is useful for ensuring efficient use of fixes, but was not used much by the New York TRACON as it did not include enough airports to be truly useful. It is thus recommended that DSP be further developed to include more airports. ITWS has been well received and is used routinely. According to a study by Lincoln Laboratories [11] it is responsible for an annual delay reduction of over 49,000 hours.

However controllers expressed a desire to see the system applied further afield as well as within the Terminal Area. It is thus recommended that the system be extended to include weather further afield. It is also recommended that the integration of both DSP and ITWS with other decision aiding tools be considered in detail.

Because of the competitive nature of the industry in which decisions aiding tools are developed it may be necessary for some government intervention to allow efficient integration of the decision aiding tools developed. It is essential that the tools developed integrate well as simply increasing the number of tools available to controllers is likely to overload them and increase their tasks instead of decreasing them. Instead the systems developed needs to be highly integrated, operating together with a minimum of interfaces to controllers. This may require certain information about system design to be made available to other contractors, when this information would normally be withheld for competitive reasons.

According to the study by Davison and Hansman on communication and coordination issues in the NAS [11] the organizational structure is ambiguous. The formation of the ATCSCC has led to a centralized control structure, with authority centralized to the ATCSCC. However, each ATC facility ultimately still functions autonomously, revealing a more decentralized structure at the local level. As identified by Davison and Hansman, further centralization of authority to the ATCSCC would reduce the ambiguity of the organizational structure. A number of other themes are visible, such as information flow issues, awkward and unorganized communications and coordination, and organizational cultural issues.

Increased utilization of runway 11-29 would add capacity, but it is significantly limited by operational interaction issues with particularly Teterboro and LaGuardia; its length, with many aircraft types not able to operate on the runway; and operational issues related to crossing the parallel runways. It is particularly recommended that efforts be taken within the system to improve coordination with Teterboro and LaGuardia to allow increased utilization of the runway. However, this should also be addressed in detail in the re-design of the New York airspace. This may require the introduction of new FAA procedures between the three airports.

The New York airspace redesign, part of the FAAs National Airspace System Operational Evolution Plan, is a top priority to alleviate congestion at the New York airports. It is thus thought to be the response to delays likely to have the greatest impact on reducing delays in the New York Metroplex, and at Newark airport. The careful development of the New York airspace redesign is thus essential.

\section{Extension to Other Airports}

Despite the continued increase in delays system wide, responses at Newark and within the facilities in New York have led to a significant 
reduction in the growth of delays at the airport, compared to the growth system wide. System wide delays in the United States increased from 1998 to 1999 by $22 \%$, with only a $3.4 \%$ increase in capacity. From 1999 to 2000 the increase was 20\%, with only a $0.4 \%$ increase in capacity. At Newark airport however after delays increased by $14.1 \%$ from 1998 to 1999 with a $0.2 \%$ increase in operations, from 1999 to 2000 delays only increased by $1.6 \%$ with a $1.3 \%$ decrease in operations. The responses to delays have reduced the growth of delays at the airport, and may thus be beneficial to reduce the growth of delays at other airports. However, the only response expected to further reduce delays significantly, at Newark, is the New York airspace redesign.

Because delays at Newark are caused by downstream flow constraints, the responses at the airport can be applied to all other airports generally as delays from downstream constraints increase. The responses at Newark will not address local problems at other airports, but an increase in delays system wide from downstream constraints is inevitable as the system becomes more congested.

\section{References}

[1] DOT, 2001, Air Carrier Traffic Statistics Monthly, Washington DC, U.S. Department of Transportation, Bureau of Transportation Statistics, http://www.bts.gov/transtu/indicators/Mobilit $\mathrm{y} / \mathrm{html} /$ Enplanements_on_Domestic_Flights.h tml.

[2] FAA, 2002, OPSNET: Ranking Report, Washington DC, Air Traffic Operations Network (OPSNET), Office of Public Affairs, Federal Aviation Authority, http://www.apo.data.faa.gov/faaopsnetall.HT M.

[3] FAA, 2001, Air Traffic Delay Information, Washington DC, Office of Public Affairs, Federal Aviation Authority, http://www.faa.gov/newsroom.htm

[4] Swierenga D., 2000, Air Transportation report on delays - 1999, Washington DC, Air Transportation Association, http://www.airtransport.org/public/industry/delays.pdf.
[5] Swierenga D., 2001, Air Transportation report on delays -2000 , Washington DC, Air Transportation Association, http://www.airtransport.org/public/industry/bin/Delays501.pdf.

[6] Allan S.S., Gaddy S.G., and Evans J.E., 2001, Delay Causality and Reduction at the New York City Airports Using Terminal Weather Information Systems, Project Report ATC291, Lexington, MA, Lincoln Laboratory, Massachusetts Institute of Technology.

[7] NOAA, 2002, National Climate Center, National Oceanic and Atmospheric Administration, http://lwf.ncdc.noaa.gov/oa/climate/stationloc ator.html.

[8] FAA, 2001, MITRE/CAASD, Airport Capacity Benchmarks 2001, Washington DC Federal Aviation Authority.

[9] Garvey, J., 2001, Statement by Jane F Garvey, FAA Administrator, Before the Committee on Transportation \& Infrastructure, Subcommittee on Aviation, on Air Traffic Congestion in the NY City Area, 7/16/01, Washington DC, Federal Aviation Authority, www.faa.gov/apa/TESTIMONY/2001/716tej g.htm.

[10] Computer Sciences Corporation, 20001, A Trip Through DSP, Egg Harbor Township, NJ, Computer Sciences Corporation.

[11] Davison, H. and Hansman, R.J., 2001, Identification of Communication and Coordination Issues on the US Air Traffic Control System, Report No. ICAT-2001-2, Cambridge, MA, Department of Aeronautics and Astronautics, Massachusetts Institute of Technology.

[12] FAA, 2000, Newark International Airport Standard Operating Procedure, EWRT 7210.17C, Washington DC, Federal Aviation Authority.

[13] FAA, 2001, NAS Operational Evolution V3.0, Washington DC, Federal Aviation Authority, http://www.caasd.org/nas-evol/index.html.

[14] Ted Gogoll, 2001, U.S. Congress Looks At 
New York Congestion; Could Cut Capacity, New York, NY, Aviation Week's www.AviationNow.com.

[15] FAA, 2001, Pre-Scoping Summary Report, New York/New Jersey Metropolitan Area Airspace Redesign Program, Washington DC, Federal Aviation Authority, Eastern Region. 